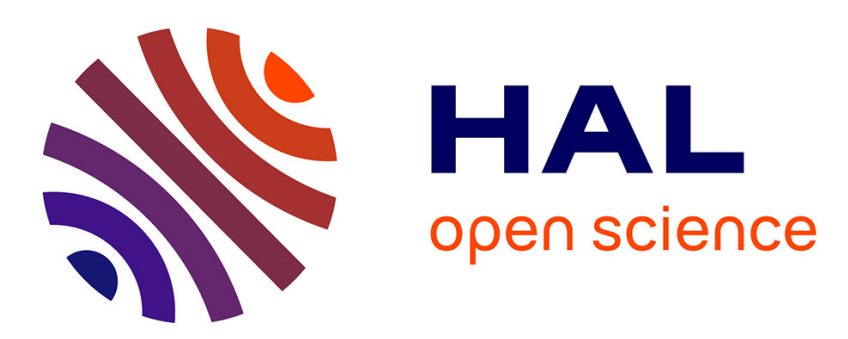

\title{
The infrared emission spectrum of $\mathrm{SiN}$ between 2.2 and $4.4 \mu \mathrm{m}$
}

\author{
M. Elhanine, B. Hanoune, G. Guelachvili, C. Amiot
}

\section{To cite this version:}

M. Elhanine, B. Hanoune, G. Guelachvili, C. Amiot. The infrared emission spectrum of SiN between 2.2 and $4.4 \mu \mathrm{m}$. Journal de Physique II, 1992, 2 (4), pp.931-938. 10.1051/jp2:1992176. jpa-00247682

\section{HAL Id: jpa-00247682 https://hal.science/jpa-00247682}

Submitted on 1 Jan 1992

HAL is a multi-disciplinary open access archive for the deposit and dissemination of scientific research documents, whether they are published or not. The documents may come from teaching and research institutions in France or abroad, or from public or private research centers.
L'archive ouverte pluridisciplinaire HAL, est destinée au dépôt et à la diffusion de documents scientifiques de niveau recherche, publiés ou non, émanant des établissements d'enseignement et de recherche français ou étrangers, des laboratoires publics ou privés. 


\title{
The infrared emission spectrum of SiN between 2.2 and $4.4 \mu \mathrm{m}$
}

\author{
M. Elhanine $\left({ }^{1}\right)$, B. Hanoune $\left({ }^{1}\right)$, G. Guelachvili $\left({ }^{1}\right)$ and C. Amiot $\left({ }^{2}\right)$ \\ (1) Laboratoire de Physique Moléculaire et Applications, UPR 136, Université de Paris-Sud, \\ Bât. 350, 91405 Orsay, France \\ (2) Laboratoire Aimé Cotton, CNRS II, Université de Paris-Sud, Bât. 505, 91405 Orsay, France
}

(Received 20 December 1991, accepted 21 January 1992)

\begin{abstract}
The emission spectrum of a plasma of silane and nitrogen, excited by a radio frequency discharge, has been recorded with a high resolution Fourier transform spectrometer. We report here the first observation by IR spectroscopy of the $\mathrm{X}^{2} \Sigma^{+}(v=1,2)$ and $\mathrm{A}^{2} \Pi_{1}(v=2,3,4)$ vibrational levels of ${ }^{28} \mathrm{Si}^{14} \mathrm{~N}$, through the observation of 724 unperturbed transitions of the (1-0), (2-0), (2-1), (3-1), and (4-2) vibronic bands of the $\mathrm{A}^{2} \Pi_{1}-\mathrm{X}^{2} \Sigma^{+}$system of this radical. The data were analyzed in a least squares fit procedure, with a standard deviation equal to $6 \times 10^{-4} \mathrm{~cm}^{-1}$
\end{abstract}

\section{Introduction.}

Since silicon is chemically similar to carbon, the astrophysicists expect the silicon-containing molecules, analogous to the carbon-containing species already detected, to be present in space where until now only $\mathrm{SiO}$ [1], SiS [2], $\mathrm{SiC}_{2}$ [3], $\mathrm{SiC}$ [4], $\mathrm{SiC}_{4}$ [5], $\mathrm{SiH}_{4}$ [6] and $\mathrm{SiN}$ [7] have been detected. Although the existence of this latter species was predicted for long by theoretical studies [8-11], it was likely observed only very recently. As the pure rotational lines of SiN have proved very difficult to detect in space, the knowledge of the A-X system, which occurs in the atmospherical infrared windows, can be of great use for the observation of this species.

The two lower electronic states of $\mathrm{SiN}, \mathrm{X}^{2} \Sigma^{+}$and $\mathrm{A}^{2} \Pi_{1}$ and the following $\mathrm{B}^{2} \Sigma^{+}$and $\mathrm{D}^{2} \Pi$ states, are known since the first studies by Jevons [12] and Mulliken [13]. The identification of the next state $\mathrm{L}^{2} \Pi$ is due to Bredohl et al. [14]. This paper contains references to all the previous works which will not be repeated here. A further step in the knowledge of the SiN radical was made by Yamada et al. [15] who observed the (0-0) band of the isotopic species of SiN by millimeter- and submillimeter-wave spectroscopy and fixed the location of the $\mathrm{A}^{2} \Pi_{1}$ state with respect to the ground electronic state at $\mathrm{T}_{\mathrm{e}}\left(\mathrm{A}^{2} \Pi_{1}\right)=2032.4 \mathrm{~cm}^{-1}$, allowing the determination of the position of the other ${ }^{2} \Pi$ electronic states. All these results have been summarized by Foster [16], who fitted all the available band origin data, namely Bredohl's results [14] in the visible and near UV spectral region (3 100-5 $600 \AA$, concerning the D-A, L-A, B-A, B-X systems) complemented with Foster's paper [17] where the B-A system and the results of the last three studies on the A-X 
system in the $3.3 \mu \mathrm{m}$ (1-0 band) region [18] and $5 \mu \mathrm{m}(0-0$ band) region $[15,19]$ are reanalyzed. The microwave spectrum of $\operatorname{SiN}$ in the $\mathrm{X}^{2} \Sigma^{+}(v=0)$ and $(v=1)$ levels was studied by Saito et al. [20] and Yamada et al. [15], leading to the most accurate measurements.

\section{Experimental results.}

The SiN radical is produced in a flowing mixture of $\mathrm{N}_{2}$ and $\mathrm{SiH}_{4}$ excited in a radio frequency discharge. The experimental setup consists of a plasma reactor [21] connected to a steppingmode Fourier transform spectrometer [22]. The experimental conditions are the same as those which enabled the detection of the HNSi molecule [23]. The optical path is adjusted in the reactor through a White-type multireflection system to about $100 \mathrm{~m}$, corresponding to a plasma column 30-50 $\mathrm{m}$ long. The plasma pressure and the rf power are set to respectively $70 \mathrm{mtorr}$ and $720 \mathrm{~W}$. The infrared emission is collected and sent to the interferometer equipped with a $\mathrm{CaF}_{2}$ beamsplitter and liquid nitrogen cooled InSb detectors. The spectral range is limited by the optical filters and the detectors to the domain $2265-4530 \mathrm{~cm}^{-1}$.

Two scans were recorded during seven hours each, with the maximal apodized resolution of $0.0054 \mathrm{~cm}^{-1}$. They differ by the $\mathrm{N}_{2}$ to $\mathrm{SiH}_{4}$ ratio, that was set at 16 for the first spectrum, and at 1.6 for the second spectrum.

Figure 1 shows a part of the first spectrum. This spectrum contains a number of lines that are absent from the second one. Some of them correspond to the $\mathrm{A}^{2} \Pi_{1}(v=1)-\mathrm{X}^{2} \Sigma^{+}(v=0)$ transition of SiN given by Foster et al. [18]. Through an iterative procedure with direct approach, we assigned the new lines from this band and from the previously unknown (2-0), (2-1), (3-1) and (4-2) bands of this system. 724 unperturbed lines of the spectrum were observed with a signal-to-noise ratio of about 15 . The distribution
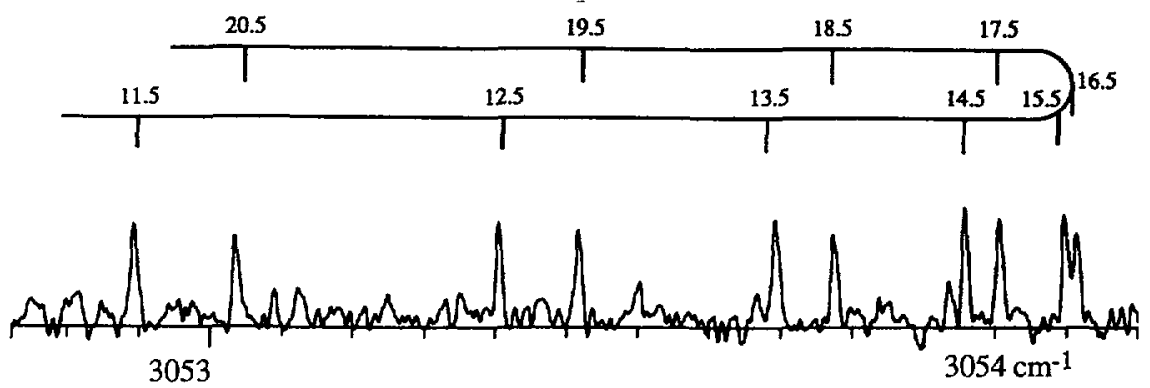

Fig. 1. - High resolution spectrum of the emission from the $\left(\mathrm{N}_{2}+\mathrm{SiH}_{4}\right)$ rf discharge $\left(\mathrm{R}_{21}(J)\right.$ branch of the (1-0) band of $\mathrm{SiN}$ ). With Resolution : $0.0054 \mathrm{~cm}^{-1}$, rf Power : $720 \mathrm{~W}, \mathrm{P}: 70 \mathrm{mtor}, \mathrm{N}_{2} / \mathrm{SiH}_{4}=16$.

Table I. - Distribution of the observed lines in the different bands.

\begin{tabular}{ccc}
\hline \hline Band & Maximum observed J value & Number of lines \\
\hline$(1-0)$ & 51.5 & 313 \\
$(2-0)$ & 47.5 & 131 \\
$(2-1)$ & 32.5 & 84 \\
$(3-1)$ & 48.5 & 121 \\
$(4-2)$ & 30.5 & 75 \\
\hline
\end{tabular}


of the lines in the different bands is given in table I. We failed to detect any other band, which is not surprising since the Franck-Condon factors and the concentration are not high enough.

We observed transitions for $J$ values up to 51.5 whereas in the former infrared studies [15, $18,19]$ the highest observed $J$ value was 31.5 . This allowed us to include in the Hamiltonian high order distortion terms that have not been taken into account previously.

\section{Theory and analysis.}

The effective Hamiltonian used in the present analysis has been developed by Brown $e t$ al. [24]:

$$
H=H^{0}+H^{\text {rot }}+H^{\text {fs }}
$$

$H^{0}$ is the vibrational-electronic part of the Hamiltonian.

$H^{\text {rot }}$ is the rotational Hamiltonian and has the form :

$$
H^{\mathrm{rot}}=B(r) \mathbf{R}^{2}=B(r)(\mathbf{J}-\mathbf{L}-\mathbf{S})^{2} .
$$

As the molecule rotates, it swells in size, and we take into account the rotational stretching by adding to the rotational Hamiltonian a quartic centrifugal distortion term : $-D(r) \mathbf{R}^{4}$ [25].

$H^{\mathrm{fs}}$ is the fine-structure Hamiltonian. It takes into account two contributions, the spin-orbit and the spin-rotation interactions :

$$
H^{\text {fs }}=H^{\text {so }}+H^{\text {sr }}
$$

These two parts have a complex microscopic form and are described with the usual phenomenological expressions :

and

$$
H^{\text {so }}=A(r) \mathbf{L} \cdot \mathbf{S}
$$

$$
H^{\mathrm{sr}}=\gamma(r) \mathbf{R} \cdot \mathbf{S}=\gamma(r)(\mathbf{J}-\mathbf{L}-\mathbf{S}) \cdot \mathbf{S} .
$$

We disregard here in the fine-structure Hamiltonian the spin-spin interaction $H^{\text {ss }}$ which vanishes in the case of doublet states, and the hyperfine-structure Hamiltonian $H^{\text {hfs }}$ (which includes the effects of the nuclear moments in interaction with the electronic and magnetic fields of the diatomic) since these effects are not observed at our resolution.

The Hamiltonian actually used is constructed by applying the perturbation theory with the Van Vleck transformation [26], and consists of two matrices representing respectively the ${ }^{2} \Sigma^{+}$and the ${ }^{2} \Pi_{1}$ Born-Oppenheimer states. The parameters of the $A$-doubling interaction resulting from the perturbation of the $\mathrm{A}^{2} \Pi_{1}$ state by both the $\mathrm{X}$ and $\mathrm{B}^{2} \Sigma$ states, but mainly by the ground state, are included as corrections elements inside the Born-Oppenheimer states matrices. Each matrix is splitted into two symmetry blocks corresponding to e and $f$ levels.

The effective matrix elements for the $\mathrm{X}^{2} \Sigma^{+}$state are :

$$
\langle\Sigma|H| \Sigma\rangle=T_{\mathrm{v}}-B_{\mathrm{v}} Z(-Z \pm 1)-D_{\mathrm{v}} Z^{2}(-1 \pm Z)^{2}-\frac{1}{2}(-Z \pm 1)\left[\gamma_{\mathrm{v}}-\gamma_{\mathrm{v} J} Z(-Z \pm 1)\right]
$$

with $Z=J+1 / 2$.

For the $\mathrm{A}^{2} \Pi_{1}$ state, we used the effective Hamiltonian of Brown et al. [24], and a basis set of Hund's case (a) wavefunctions. The second order expansion of the Hamiltonians has been found to be necessary to fit our data. 
The effective Hamiltonian matrix elements for the $\mathrm{A}^{2} \Pi_{\mathrm{i}}$ state are :

$$
\begin{aligned}
& \left\langle\Pi_{1 / 2}|H| \Pi_{1 / 2}\right\rangle=T_{\mathrm{v}}-\frac{A_{\mathrm{v}}}{2}+\left(B_{\mathrm{v}}-\frac{A_{\mathrm{v} D}}{2}\right)(X+2)-D_{\mathrm{v}}(X+1)(X+4)- \\
& -\frac{1}{2}\left[p_{\mathrm{v}}+p_{\mathrm{v} J} J(J+1)\right](-1 \pm \sqrt{X+1})-\frac{1}{2}\left[q_{\mathrm{v}}+q_{\mathrm{v} J} J(J+1)\right](-X-2 \pm 2 \sqrt{X+1}) \\
& \left\langle\Pi_{3 / 2}|H| \Pi_{3 / 2}\right\rangle=T_{\mathrm{v}}+\frac{A_{\mathrm{v}}}{2}+\left(B_{\mathrm{v}}+\frac{A_{\mathrm{v} D}}{2}\right) X-D_{\mathrm{v}} X(X+1)+\frac{1}{2} X\left[q_{\mathrm{v}}+q_{\mathrm{v} J} J(J+1)\right] \\
& \left\langle\Pi_{3 / 2}|H| \Pi_{1 / 2}\right\rangle=\left[2 D_{\mathrm{v}}(X+1)-B_{\mathrm{v}}+\frac{1}{4}\left[p_{\mathrm{v}}+p_{\mathrm{v} J} J(J+1)\right]+\right. \\
& \left.+\frac{1}{2}\left[q_{\mathrm{v}}+q_{\mathrm{v} J} J(J+1)\right](-1 \pm \sqrt{X+1})\right] \sqrt{X}
\end{aligned}
$$

where $X=(J+1 / 2)^{2}-1$.

In all these formulae, the upper sign refers to the e-levels, and the lower sign to the f-levels. The $e$ and $f$ labelling is done according to the recommendations of reference [27].

The energy levels are obtained by diagonalizing the blocks of the matrix constructed for each $J$-value. The transitions are then calculated by applying the selection rules :

$$
\begin{aligned}
& \Delta J= \pm 1: \mathrm{e} \leftrightarrow \mathrm{e}, \mathrm{f} \leftrightarrow \mathrm{f} \\
& \Delta J=0: \mathrm{e} \leftrightarrow \mathrm{f} .
\end{aligned}
$$

\section{Results and discussion.}

Two fits were performed for the analysis of this system. In the first one we treated simultaneously all the unperturbed line wavenumbers of the (1-0), (2-0), (2-1), and (3-1) bands, together with the data of the (0-0) band given in the references [15] and [19]. We included also the lines of the (1-0) band measured by Foster et al. [18] but not observed in the present work. The second calculation treated the (4-2) band alone. This two fit procedure could not be avoided since the vibronic levels involved in this band are different from the levels of the other bands. The RMS deviation for each fit is about $6 \times 10^{-4} \mathrm{~cm}^{-1}$. The molecular constants are summarized in table II for the $\mathrm{X}^{2} \Sigma^{+}$state and in table III for the

Table II. - Molecular parameters of ${ }^{28} \mathrm{SiN}$ in the $\mathrm{X}^{2} \Sigma^{+}$state $\left(\right.$in $\left.\mathrm{cm}^{-1}\right)$. The numbers in parentheses represent one standard deviation in units of the last digit.

\begin{tabular}{rlcc}
\hline & $\mathrm{v}=0$ & $\mathrm{v}=1$ & $\mathrm{v}=2^{\mathrm{a}}$ \\
\hline $\mathrm{T}$ & $0^{\mathrm{b}}$ & $1138.37420(26)$ & $2263.83945(30) \mathrm{c}$ \\
$\mathrm{B}$ & $0.7280952(32)$ & $0.7224925(32)$ & $0.716972(14)$ \\
$10^{5} \mathrm{D}$ & $0.11760(21)$ & $0.11808(22)$ & $0.1226(15)$ \\
$10^{2} \gamma$ & $1.6853(12)$ & $1.9604(11)$ & $1.3430(41)$ \\
$10^{5} \gamma_{\mathrm{J}}$ & $0.0116(15)$ & $0.0505(18)$ & $0.1310(91)$ \\
\hline \hline
\end{tabular}

a The results in this column come from the fit of the (4-2) band alone.

b Fixed

$c_{\text {Relative to }} \mathrm{T}_{4}\left(\mathrm{~A}^{2} \Pi\right)$. See text and Table III. 
Table III. - Molecular parameters of ${ }^{28} \mathrm{SiN}$ in the $\mathrm{A}^{2} \Pi_{\mathrm{i}}$ state $\left(\right.$ in $\left.\mathrm{cm}^{-1}\right)$. The numbers in parentheses represent one standard deviation in units of the last digit.

\begin{tabular}{rlllll}
\hline & $\mathrm{v}=0$ & $\mathrm{v}=1$ & $\mathrm{v}=2$ & $\mathrm{v}=3$ & $\mathrm{v}=4^{\mathrm{a}}$ \\
\hline $\mathrm{T}$ & $1971.774771(90)$ & $2991.353782(63)$ & $3998.54016(15)$ & $4993.30588(30)$ & $5975.6233^{\mathrm{b}}$ \\
$\mathrm{A}$ & $-89.09357(17)$ & $-88.87314(12)$ & $88.67265(21)$ & $88.48635(28)$ & $-88.30789(44)$ \\
$10^{4} \mathrm{~A}_{\mathrm{J}}$ & $0.549(10)$ & $0.5451(14)$ & $0.5887(48)$ & $0.6688(70)$ & $0.719(14)$ \\
$\mathrm{B}$ & $0.6673586(24)$ & $0.66191761(33)$ & $0.6564594(32)$ & $0.6509795(33)$ & $0.645508(15)$ \\
$10^{5} \mathrm{D}$ & $0.11325(26)$ & $0.113133(17)$ & $0.11348(22)$ & $0.11367(23)$ & $0.1174(17)$ \\
$10^{3} \mathrm{p}$ & $6.302(28)$ & $1.946(11)$ & $0.628(18)$ & $1.508(22)$ & $1.291(68)$ \\
$10^{4} \mathrm{q}$ & $0.111(45)$ & $0.2265(65)$ & $0.442(12)$ & $0.547(14)$ & $-0.507(78)$ \\
$10^{5} \mathrm{p}_{\mathrm{J}}$ & $0.1200(62)$ & $0.13933(96)$ & $0.1215(21)$ & $0.0742(24)$ & $0.049(15)$ \\
$10^{7} \mathrm{q}_{\mathrm{J}}$ & $0.214(52)$ & $0.1399(38)$ & $0.084(11)$ & $0.051(10)$ & not signficant \\
\hline \hline
\end{tabular}

a The results in this column come from the fit of the (4-2) band alone.

${ }^{b}$ Fixed at the value estimated after expanding the first four $T_{V}\left(A^{2} \Pi\right)$ in power of $(v+0.5)$.

A ${ }^{2} \Pi_{\mathrm{i}}$ state. All parameters were free, with the exception of the vibronic terms $T_{0}\left(\mathrm{X}^{2} \Sigma^{+}\right)$and $T_{4}\left(\mathrm{~A}^{2} \Pi_{\mathrm{i}}\right.$ ), that were set respectively at 0 and $5975.623 \mathrm{~cm}^{-1}$ This extrapolated value of $T_{4}\left(\mathrm{~A}^{2} \Pi_{\mathrm{i}}\right.$ ) has been estimated by expanding the first four vibrational terms of the excited state using the usual development :

$$
T_{\mathrm{v}}=T_{\mathrm{e}}+\omega_{\mathrm{e}}(v+1 / 2)-\omega_{\mathrm{e}} x_{\mathrm{e}}(v+1 / 2)^{2}+\omega_{\mathrm{e}} y_{\mathrm{e}}(v+1 / 2)^{3}
$$

As a result of this procedure, the (4-2) band origin $\left(3711.78655(30) \mathrm{cm}^{-1}\right.$ computed in the second fit made possible to fix up $T_{2}\left(X^{2} \Sigma^{+}\right)$at $2263.839(42) \mathrm{cm}^{-1}$ The equilibrium vibrational constants of the ground state were derived up to the first anharmonic correction $\omega_{\mathrm{e}} x_{\mathrm{e}}$, since only three vibrational terms are available.

The equilibrium rotational constants were obtained through a least squares fit of the set of $B_{\mathrm{y}}$ constants for the vibrational levels, with the usual sign conventions :

$$
B_{\mathrm{v}}=B_{\mathrm{e}}-\alpha_{\mathrm{e}}(v+1 / 2)-\beta_{\mathrm{e}}(v+1 / 2)^{2}
$$

Table IV shows the equilibrium constants of the $\mathrm{X}$ state. Our results are in good agreement with the published ones. Since the position of the $\mathrm{X}^{2} \Sigma^{+}(v=2)$ level is not known with a sufficient accuracy, we preferred not to take into account the value of $\omega_{\mathrm{e}} y_{\mathrm{e}}=-0.69 \times 10^{-2} \mathrm{~cm}^{-1}$ given by Foster [16]. Introducing this value leads to values for $\omega_{\mathrm{e}}$ and $\omega_{\mathrm{e}} x_{\mathrm{e}}$ slightly lower than reported, but remaining still in the uncertainty limits of Foster.

For the $\mathrm{A}^{2} \Pi_{\mathrm{i}}$ state, the comparison of the vibrational constants cannot be made straightforwardly because Foster used Zare's « unique perturber approximation » [28]. Instead of applying transformation relationships between the two formulations [24], what can lead to biased results if the parameters are correlated, a second analysis was performed using Zare's Hamiltonian. This led to another set of molecular and equilibrium parameters. The results of both analysis are given in table $V$. The difference between the two values of $T_{\mathrm{e}}\left(\mathrm{A}^{2} \Pi\right)$ comes from a different definition of this constant in Zare's Hamiltonian, where it includes also the rotational constant $B_{\mathrm{e}}$ [29]. Nevertheless, our vibrational development shows quite large discrepancies with Foster's one. We ascribe these discrepancies to the fact 
Table IV. - Equilibrium parameters of ${ }^{28} \mathrm{SiN}$ in $\mathrm{X}^{2} \Sigma^{+}$state (in $\left.\mathrm{cm}^{-1}\right)$. The numbers in parentheses represent one standard deviation in units of the last digit.

\begin{tabular}{rlll}
\hline & This work & Previous works & \multicolumn{1}{c}{ Refs } \\
\hline \hline $\mathrm{B}_{\mathrm{e}}$ & $0.730927(15)$ & $0.7311(1)$ & Bredohl et al.(14) \\
$10^{3} \alpha_{\mathrm{e}}$ & $5.685(30)$ & $5.65(3)$ & Bredohl et al.(14) \\
$10^{4} \beta_{\mathrm{e}}$ & $4.1(12)$ & & \\
\hline $\mathrm{T}_{\mathrm{e}}$ & $0^{\mathrm{a}}$ & $0^{\mathrm{a}}$ & \\
$\omega_{\mathrm{e}}$ & $1151.284(43)$ & $1151.30(11)$ & Foster (16) \\
$\omega_{\mathrm{e}} \mathrm{x}_{\mathrm{e}}$ & $6.455(21)$ & $6.463(28)$ & Foster (16) \\
$10^{2} \omega_{\mathrm{e}} \mathrm{y}_{\mathrm{e}}$ & & $-0.69(20)$ & Foster (16) \\
\hline
\end{tabular}

aFixed.

Table V. - Equilibrium parameters of ${ }^{28} \mathrm{SiN}$ in the $\mathrm{A}^{2} \Pi_{\mathrm{j}}$ state $\left(\right.$ in $\mathrm{cm}^{-1}$ ). The numbers in parentheses represent one standard deviation in units of the last digit.

\begin{tabular}{|c|c|c|c|c|}
\hline & \multicolumn{2}{|c|}{ This work } & \multirow{2}{*}{$\begin{array}{c}\text { Previous works } \\
\text { Zare's hamiltonian } \\
\end{array}$} & \multirow[t]{2}{*}{ Refs } \\
\hline & Brown's hamiltonian & Zare's hamiltonian & & \\
\hline $\mathrm{B}_{\mathbf{e}}$ & $0.6700793(93)$ & $0.6700771(95)$ & $0.6700904(11)$ & Yamada et al.(15) \\
\hline $10^{3} \alpha_{\mathrm{e}}$ & $5.4344(88)$ & $5.4345(89)$ & $5.4546(11)$ & Yamada et al. (15) \\
\hline $10^{6} \beta_{\mathrm{e}}$ & $5.9(17)$ & $5.9(17)$ & & \\
\hline $\mathbf{T}_{\mathbf{e}}$ & $2031.375(16)$ & $2032.045(49)$ & $2032.15(6)$ & Foster (16) \\
\hline$\omega_{\mathrm{e}}$ & $1031.9448(15)$ & $1031.9393(17)$ & $1031.65(5)$ & Foster (16) \\
\hline$\omega_{\mathrm{e}} x_{\mathrm{e}}$ & $6.17531(95)$ & $6.1753(11)$ & $5.989(29)$ & Foster (16) \\
\hline $10^{2} \omega_{\mathrm{eye}}$ & $-0.467(17)$ & $-0.467(20)$ & $-3.02(35)$ & Foster (16) \\
\hline
\end{tabular}

that the weight attributed to the A state in his calculation was too small compared to the weight of the higher states.

\section{Conclusion.}

The interpretation of the behavior of the $A$-doubling and spin-orbit coupling parameters in the A state and of the spin-rotation constants in the X state in term of interaction between the vibrational levels of these two states has been discussed by Foster et al. [18] and Yamada $e t$ al. [15], who ascribe the drastic and irregular changes of these constants versus $v$, specially of $p$, $q$, and $\gamma$, to the fact that the A-X separation is comparable with the vibrational energy. Table VI shows the results of the present work together with the values reported by Yamada et al. [15]. The two experimental sets of parameters are in good agreement. The values computed in reference [15] are obtained by expanding the theoretical expressions of the $A$ doubling constants as a product of electronic and vibrational integrals, and fitting the electronic integrals, while the vibrational integrals are evaluated numerically from an RKR 
Table VI. - Comparison between the experimental and calculated values of ${ }^{28} \mathrm{SiN}$ for the $\mathrm{p}, \mathrm{q}$, and $\mathrm{A}$ constants of the $\mathrm{A}^{2} \Pi$ state, and the $\gamma$ constants of the $\mathrm{X}^{2} \Sigma^{+}$state $\left(\mathrm{cm}^{-1}\right)$.

\begin{tabular}{|c|c|c|c|}
\hline & This work & Previous work (15) & Computed value (15) \\
\hline $\begin{aligned} 10^{3} \mathrm{p}_{\mathrm{v}} \\
\mathrm{v}=0 \\
\mathrm{v}=1 \\
\mathrm{v}=2 \\
\mathrm{v}=3 \\
\mathrm{v}=4\end{aligned}$ & $\begin{array}{r}6.302(28) \\
1.946(11) \\
-0.628(18) \\
-1.508(22) \\
-1.291(68) \\
\end{array}$ & $\begin{array}{l}6.261(18) \\
1.892(31)\end{array}$ & $\begin{array}{r}6.244 \\
1.940 \\
-0.723 \\
-1.831 \\
-1.642 \\
\end{array}$ \\
\hline $\begin{aligned} & 10^{4} \mathrm{q}_{\mathrm{v}} \\
& \mathrm{v}=0 \\
& \mathrm{v}=1 \\
& \mathrm{v}=2 \\
& \mathrm{v}=3 \\
& \mathrm{v}=4\end{aligned}$ & $\begin{array}{c}0.111(45) \\
-0.2265(65) \\
-0.442(12) \\
-0.547(14) \\
-0.507(78) \\
\end{array}$ & $\begin{array}{r}0.121(37) \\
-0.159(17)\end{array}$ & $\begin{array}{r}0.185 \\
-0.174 \\
-0.396 \\
-0.488 \\
-0.471 \\
\end{array}$ \\
\hline $\begin{array}{ll}A_{v} & \\
v=0 \\
v=1 \\
v=2 \\
v=3 \\
v=4\end{array}$ & $\begin{array}{r}-89.09357(17) \\
88.87314(12) \\
-88.67265(21) \\
-88.48635(28) \\
-88.30789(44)\end{array}$ & $\begin{array}{l}-89.09657(18) \\
-88.87320(22) \\
88.65(2)^{a} \\
-88.32(2)^{b} \\
\end{array}$ & $\begin{array}{l}-89.097 \\
-88.873 \\
-88.665 \\
-88.469 \\
-88.284 \\
\end{array}$ \\
\hline $\begin{array}{r}10^{2} \gamma_{v} \\
v=0 \\
v=1 \\
v=2\end{array}$ & $\begin{array}{l}1.6853(12) \\
1.9604(11) \\
1.3430(41)\end{array}$ & $\begin{array}{l}1.684862(57) \\
1.97317(17)\end{array}$ & $\begin{array}{l}1.685 \\
1.966 \\
1.384\end{array}$ \\
\hline
\end{tabular}

calculation. They do not match closely the experimental results, but they show the same behavior, and can be useful for the detection of the hot bands, since the difficulties in observing the lines do not come from the approximated values of the constants but from the weakness of the transitions. For this reason, we did not perform similar calculations, even though our experimental results should improve the prediction of the parameters. Since the perturbation is expected to be maximal [15] in the $\mathrm{X}^{2} \Sigma^{+} v=7,8$ and $\mathrm{A}^{2} \Pi v=8$, 9 levels, the knowledge of some more vibrational levels, in the ground state as well as in the excited state, is necessary to obtain a good description of the crossing between the $\mathrm{A}^{2} \Pi$ and $\mathrm{X}^{2} \Sigma^{+}$states of $\mathrm{SiN}$.

\section{Acknowledgments.}

The experiments were undertaken after discussing with P. Bernath the need for searching for the SiN molecule. This work was supported by the CNRS «Groupe de Recherche sur la Physico-Chimie des Molécules Interstellaires ».

Note : The spectral positions of the transitions have been deposited in the Editorial Office of the Journal de Physique. These data are also available upon request to $\mathrm{M}$. Elhanine. 


\section{References}

[1] Wilson R. W., Penzias A. A., Jefferts K. B., Kutner M. and Thaddeus P., Astrophys. J. 167 (1971) L97.

[2] Morris M., Gilmore W., Palmer P., Turner B. E. and Zuckerman B., Astrophys. J. 199 (1975) L47.

[3] Thaddeus P., Cummins S. E. and Linke R. A., Astrophys. J. 283 (1984) L45.

[4] Cernicharo J., Gottlieb C. A., Guelin M., Thaddeus P. and VrTilek M., Astrophys. J. 341 (1989) L25.

[5] Ohishi M., Kaifu N., Kawaguchi K., Murakami A., Saito S., Yamamoto S., Ishikawa S., Fuitta Y., Shiratori Y. and IRvine W. M., Astrophys. J. 345 (1989) L83.

[6] Goldhaber D. M. and BeTZ A. L., Astrophys. J. 279 (1984) L55.

[7] TURner B. E., IAU Symposium $\mathrm{N}^{\circ} 150$, «Astrochemistry of Cosmic Phenomena », P. D. Singh Ed. (Kluwer, 1992) to be published.

[8] Herbst E., Millar T. J., Wlodek S. and Bohme D. K., Astron. Astrophys. 222 (1989) 205.

[9] Lovas F. J., Astrophys. J. 193 (1974) 265.

[10] Turner J. L. and Dalgarno A., Astrophys. J. 213 (1977) 386.

[11] Roveri R. M., ERdelyi Mendes M. and Singh P. D., Astron. Astrophys. 199 (1988) 127.

[12] Jevons W., Proc. R. Soc. London Ser. A 89 (1913) 187.

[13] Mulliken R. S., Phys. Rev. 26 (1925) 319.

[14] Bredohl H., Dubois I., Houbrechts Y. and Singh M., Can. J. Phys. 54 (1976) 680.

[15] Yamada C., HiRota E., Yamamoto S. and Saito S., J. Chem. Phys. 88 (1988) 46.

[16] Foster S. C., J. Mol. Spectr. 137 (1989) 430.

[17] Foster S. C., J. Mol. Spectr. 106 (1984) 369.

[18] Foster S. C., Lubic K. G. and Amano T., J. Chem. Phys. 82 (1985) 709.

[19] Yamada C. and Hirota E., J. Chem. Phys. 82 (1985) 2547.

[20] Saito S., Endo Y. and Hirota E., J. Chem. Phys. 78 (1983) 6447.

[21] Chollet P., Guelachyili G., Morillon-Chapey M., Gressier P. and Schmitt J. P. M., JOSA B 3 (1986) 687.

[22] Connes J., Delouis H., Connes P., Guelachyili G., Maillard J.-P. and Michel G., Nouv. Rev. Opt. Appl. 1 (1970) 3.

[23] Elhanine M., Farrene R. and Guelachvili G., J. Chem. Phys. 94 (1991) 2529.

[24] Brown J. M., Kaise M., Kerr C. M. L. and Milton D. J., Mol. Phys. 36 (1978) 553.

[25] Zare R. N., Schmeltekopf A. L., Albritton D. L. and Harrop W. J., J. Mol. Spectr. 48 (1973) 174.

[26] VAN Vleck, Phys. Rev. 33 (1929) 467.

[27] Brown J. M., Hougen J. T., Huber K. P., Johns J. W. C., Kopp I., Lefebvre-Brion H., Merer A. J., Ramsay D. A., Rostas J, and Zare R. N., J. Mol. Spectr. 55 (1975) 500.

[28] Zare R. N., Schmeltekopf A. L., Harrop W. J. and Albritton D. L., J. Mol. Spectr. 46 (1973) 37.

[29] Brown J. M., Colbourn E. A., Watson J. K. G. and Wayne F. D., J. Mol. Spectr. 74 (1979) 294. 